\title{
The Effect of Psychological Conditions on Sexuality: A Review
}

\author{
Rokach A* \\ Center for Academic Studies, Israel and York university, Canada \\ *Corresponding author: Rokach, A. Center for Academic Studies, Israel and York university, Canada \\ Submission: 鮆 November 28, 2018; Published: 悳 February 07, 2019
}

The Effect of Psychological Conditions on

Sexuality: A Review

There is a wide variety of medical pathologies and psychological disturbances that interfere with sexual functioning and enjoyment. It is known that the majority of sexual problems are not caused by medical conditions, and those will be reviewed in this article [1].

\section{Depression and Anxiety}

Depression, a leading problem globally is frequently associated with sexual dysfunction in both genders [2]. Sexual dysfunction, meaning loss of sexual desire, loss of sexual enjoyment, sexual aversion, failure of genital response (erectile dysfunction in men and vaginal dryness or failure of lubrication in women), orgasmic dysfunction, premature ejaculation, vaginismus in women, and dyspareunia or pain during sexual intercourse 2012. Epidemiological studies found that the 12-month prevalence of at least one sexual dysfunction is between $30 \%$ and $70 \%$ in sexually active men and women in high-income countries [3,4]. People's depression affects their ability to work and function socially, and interestingly, antidepressants are known to adversely affect sexual function, which may then enhance the very depression that they are attempting to address [5].

[6], in his research on depression, found that loss of sexual interest was reported by $61 \%$ of those experiencing severe depression, compared to $21 \%$ of non-depressed [7]. Similarly, [8] compared sexual activity of depressed people to that of medically sick non-depressed patients. He found that $63 \%$ of depressed patients complained of decreased sexual activity compared to $39 \%$ of the non-depressed participants. Reduced libido affected $83 \%$ of depressed males, and $53 \%$ of depressed females. Woodruff, Murphy et al. [9] found that $23 \%$ of men with primary affective disorder reported 2009. A research that looked at men and women whose primary problem was low sexual desire who were not depressed at the time of assessment. The low sexual desire group had a significantly higher incidence of depressive illness in the past. It was found that the initial episode of depressive disorder coincided with or preceded the onset of loss sexual desire [10].
In the Zurich Cohort Study of men and women in the ages 20 to 35 an association between depression, meaning major depressive illness, dysthymia and recurrent brief episodes of depression, and loss of sexual interest was found in both genders, though it was more marked in women. Angst 1998 further reported that in that study, the loss of sexual interest was negatively correlated with generalized anxiety disorder. 2001 found that people suffering from panic disorder were more likely to encounter sexual problems, particularly sexual aversion, whereas premature ejaculation was the most common sexual problem in men with social phobias. Given the emphasis on performance anxiety of men and women, it is apparent that anxiety disorders will affect sexual performance, pleasure and satisfaction 1984. Interesting to note that the association between negative mood and sexuality is not always in the same direction.

[7] reported that of a group of depressives, while $31 \%$ have lost sexual interest, $22 \%$ reported increased sexual interest! In 1998 study, $26 \%$ of depressed men reported decreased sexual interest while $23 \%$ said that their sexual interest increased. Those perplexing results were less evident in women, where only $9 \%$ of them reported increased sexual interest, while 35\% reported that their sexual interest significantly decreased. An association between depression and sexual appetite is not surprising. And while there is a minority of men and women whose sexual interest increases when they are depressed, most people are interested in sex when they feel good, relaxed and content [11].

\section{Schizophrenia}

Given the seriousness and the significant influence that this mental illness has, it is surprising that very limited research on its affect on sexuality was carried out [1]. In earlier studies, Schizophrenics showed less decrease in sexual interest than other psychiatric patients 1966, 1967, 1984 found that sexual dysfunction was more common, both pre and post the psychotic breakdown, in the women that they studied. Of these women, $60 \%$ have never had an orgasm. Psychotic hallucinations of men commonly involve sexual content. Schizophrenics reported that $30 \%$ of their hallucinations involved genital change, and $20 \%$ 
involved sex change [1]. In Schizophrenic women the results were very similar. The continuation of sexual interest in the presence of bizarre sexual ideas, may account for the psychotic sexual behavior or sexual attacks that Schizophrenics are occasionally involved in. Most Schizophrenics do not have sexual relations, but those who do, engage in unprotected sex and thus are at high risk to contract sexually transmitted diseases [1]. Consequently, they may face partner rejection, social isolation, and loneliness.

Counseling can be very helpful to those who suffer from sexual dysfunctions and which the basis for them is not medical. It is now 50 years that issues such as erectile dysfunction, premature ejaculation, orgasmic disfunction, or dyspareunia have been treated utilizing psychological techniques geared to address the underlying causes for those dysfunctions, and to enlist the sexual partner to assist and empower the struggling one.

\section{References}

1. Bancroft J (2009) Human sexuality and its problems ( $3^{\text {rd }}$ edn), Elsevier Toronto, Canada.

2. World Health Organization (2008) The global burden of disease: 2004 update. WHO Press, Geneva, Switzerland.

3. Christensen BS, Gronbaek M, Osler M, Pedersen BV, Graugaard C, et al. (2011) Associations between physical and mental health problems and sexual dysfunctions in sexually active Danes. Journal Sex Med 8: 18901902.

4. Mercer CH, Fenton KA, Johnson AM, Wellings K, Macdowall W (2003) Sexual function problems and help seeking behaviour in Britain: National probability sample survey. BMJ 327: 426-427.

5. Serretti A, Chiesa A (2009) Treatment-emergent sexual dysfunction related to antidepressants: A meta-analysis. Journal of Clinical Psychopharmacology 29: 259-266.

6. Beck AT (1967) Depression: Clinical, experimental and theoretical aspects. Staples Press. London, England.

7. Mathew RJ, Weinman ML (1982) Sexual dysfunction in depression. Archives of Sexual Behavior 11: 323-328.

8. Cassidy WL, Flanagan N B, Spellman M, Cohen ME (1957) Clinical observations in manic depressive disease. Journal of the American Medical Association 164: 1535-1546.

9. Woodruff RA, Murphy GE, Herjanic M (1967) The natural history of affective disorders: 1 . symptoms of 72 patients at the time of index hospital admission. Journal of Psychiatric Research 5: 255-263.

10. Cyranowski JM, Bromberger J, Youk A, Matthews K, Kravitz HM, et al. (2004) Lifetime depression history and sexual function in women at midlife. Archives of Sexual Behavior 33(6): 539-548.

11. Chung SD, Chen YK, Kang JH, Keller JJ, Huang CC, et al. (2011) Populationbased estimates of medical comorbidities in erectile dysfunction in a Taiwanese population. Journal of Sex Med 8: 3316-3324.
Creative Commons Attribution 4.0 International License

For possible submissions Click Here
Submit Article

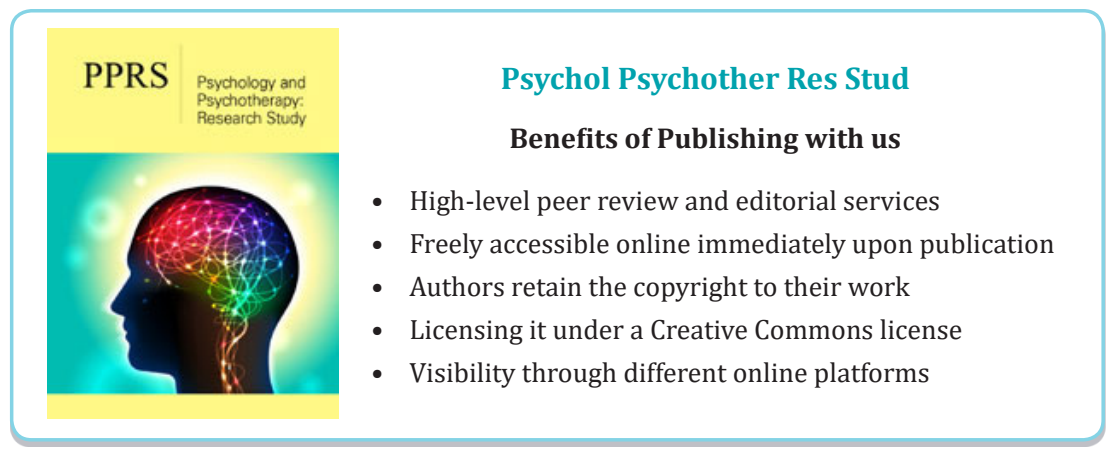

